\title{
Results of Surgery for Inflammatory Bowel Disease: A Further Survey of One Hospital Region
}

\author{
JEAN K. RITCHIE
}

British Medical fournal, 1974, 1, 264-268

\section{Summary}

Case records have been studied for the results of surgery in 294 patients operated on for inflammatory bowel disease during 1967-72 at 34 non-teaching hospitals within the North-east Metropolitan Hospital Region. All patients treated surgically for acute colitis and those treated for chronic disease by total colectomy were included.

The postoperative mortality of the primary surgery was $23.7 \%$. The mortality was $2 \cdot 1 \%$ in patients treated by elective operation, $37.6 \%$ in patients coming to urgent operation, and $60.9 \%$ in patients treated by emergency operation. The three most important factors affecting the mortality were considered to be: increasing age of the patient, the presence of established colonic dilatation, and preoperative perforation of the colon.

\section{Introduction}

Six years ago a survey was made of all patients who had had an ileostomy established for chronic inflammatory bowel disease in the hospitals of the North-east Metropolitan Hospital Region during 1955-66. ${ }^{1}$ That investigation had two main faults. The surgical results were already somewhat out of date at the time of publication and patients treated successfully by colectomy and ileorectal anastomosis were not included.

This study presents an up-to-date picture of the surgical treatment of these diseases in an unselected group of patients from all the general non-teaching hospitals in the region over the six-year period 1967-72. The data were collected during the seven months from October 1972 to May 1973.

\section{Collection of Data}

The names of the patients were obtained by studying the operation registers: the exception to this was the Chelmsford group of hospitals, where the centralized records of the pathology department were used. To overcome differences of nomenclature in operation registers, the notes of every patient undergoing colonic surgery or rectal excision were studied as far as possible. This sample may not be a total one but it is as complete as it is practicable to make it.

\section{Criteria for Inclusion}

All patients treated surgically for acute colitis were included. Patients undergoing surgery for chronic disease were included only if a total colectomy was carried out. Thus, patients treated for chronic ulcerative colitis by unusual operations-e.g., left hemicolectomy only or rectal excision alone were excluded,

TABLE I-Age and Sex Distribution of 294 Patients

\begin{tabular}{|c|c|c|c|c|c|c|}
\hline \multirow{2}{*}{ Age in Years* } & \multicolumn{2}{|c|}{ Male } & \multicolumn{2}{|c|}{ Female } & \multicolumn{2}{|c|}{ Total } \\
\hline & No. & $\%$ & No. & $\%$ & No. & $\%$ \\
\hline $\begin{array}{l}<20 \\
20-29 \\
30-39 \\
40-49 \\
50-59 \\
60-69 \\
70-79 \\
80-89\end{array}$ & $\begin{array}{r}4 \\
26 \\
20 \\
23 \\
31 \\
12 \\
6 \\
1\end{array}$ & $\begin{array}{r}3 \cdot 2 \\
21 \cdot 1 \\
16 \cdot 3 \\
18 \cdot 7 \\
25 \cdot 2 \\
9 \cdot 8 \\
4 \cdot 9 \\
0.8\end{array}$ & $\begin{array}{r}6 \\
19 \\
23 \\
37 \\
32 \\
37 \\
15 \\
2\end{array}$ & $\begin{array}{r}3.5 \\
11.1 \\
13.5 \\
21.6 \\
18.7 \\
21.6 \\
8.8 \\
1.2\end{array}$ & $\begin{array}{r}10 \\
45 \\
43 \\
60 \\
63 \\
49 \\
21 \\
3\end{array}$ & $\begin{array}{r}3.4 \\
15.3 \\
14.6 \\
20.4 \\
21.4 \\
16.7 \\
7.2 \\
1.0\end{array}$ \\
\hline Total & 123 & $100 \cdot 0$ & 171 & $100 \cdot 0$ & 294 & $100 \cdot 0$ \\
\hline
\end{tabular}

*The age of the patients at the time of the first definitive surgery is given. as were patients with Crohn's disease treated by partial colectomy -e.g., right hemicolectomy, limited colectomy for localized disease, or subtotal colectomy and ileosigmoid anastomosis.

Only patients who had the major part or all of their surgery in 1967-72 were included: 10 patients who had had an earlier colectomy and ileorectal anastomosis followed by rectal excision and ileostomy during the years 1967-72 were excluded. With these criteria, a total of 294 patients, operated on at 34 hospitals, was available for study.

In the previous survey 126 of the 453 patients studied were operated on at the teaching hospitals within the region. Where reference is made to the previous survey, these 126 patients have been omitted and the comparisons made are with the 327 patients treated at the same non-teaching hospitals as those studied in the present survey.

\section{Pathology}

No pathological report was obtainable for five patients in whom the clinical diagnosis was ulcerative colitis. A total of 38 patients was considered probably or certainly to have Crohn's disease. Interestingly, this diagnosis was made in $12.9 \%$ of the patients in this study, compared with $4.9 \%$ (16 out of 327 patients) in the previous one. This higher figure is probably due to increasing recognition of the disease by both the clinician and the pathologist rather than to an actual increase in the prevalence of largebowel Crohn's disease, but it is impossible to be certain about his.

All patients are included in the analyses which follow, irrespective of the pathological diagnosis.

\section{Clinical Details}

Out of a total of 294 patients, the ratio of women to men of $1 \cdot 4 / 1$ (table I) is the same as that found in the previous survey. The age distribution of the men is also essentially similar to that found previously; for the women, however, there was a definite increase in the older groups with $50.3 \%$ of the patients being 50 years of age or over, compared with $36.2 \%$ previously.

Table II shows that a history of less than one year was recorded in 84 patients $(29.7 \%$ of the 283 cases in which the information was available): the proportion of patients with a similar short preoperative history was the same as that found previously (29.9\% of 318 patients). 
TABLE II-Length of History in 283 Patients

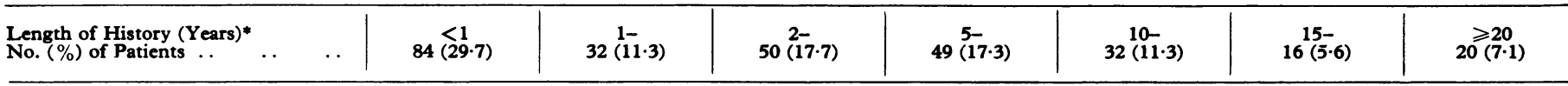

*To first definitive surgery.

TABLE III-Preoperative Grading of 621 Patients in the 1967-72 and 1955-66 Surveys

\begin{tabular}{|c|c|c|c|c|c|c|c|c|c|c|c|c|}
\hline & \multicolumn{2}{|c|}{ A } & \multicolumn{2}{|c|}{ B } & \multicolumn{2}{|c|}{ C } & \multicolumn{2}{|c|}{ D } & \multicolumn{2}{|c|}{ Unknown } & \multicolumn{2}{|c|}{ Total } \\
\hline & No. & $\%$ & No. & $\%$ & No. & $\%$ & No. & $\%$ & No. & $\%$ & No. & $\%$ \\
\hline $\begin{array}{l}1967-72 \\
1955-66\end{array}$ & $\begin{array}{r}15 \\
4\end{array}$ & $\begin{array}{l}5 \cdot 1 \\
1 \cdot 2\end{array}$ & $\begin{array}{l}125 \\
123\end{array}$ & $\begin{array}{l}42.5 \\
37.6\end{array}$ & $\begin{array}{l}85 \\
97\end{array}$ & $\begin{array}{l}28.9 \\
29.7\end{array}$ & $\begin{array}{l}46 \\
46\end{array}$ & $\begin{array}{l}15 \cdot 7 \\
14 \cdot 1\end{array}$ & $\begin{array}{l}23 \\
57\end{array}$ & $\begin{array}{r}7 \cdot 8 \\
17 \cdot 4\end{array}$ & $\begin{array}{l}294 \\
327\end{array}$ & $\begin{array}{l}100 \\
100\end{array}$ \\
\hline
\end{tabular}

A-D = Grading of severity of disease preoperatively (see text).

The preoperative severity of the disease was assessed using the criteria of Ewart and Lennard-Jones. ${ }^{2}$ In this classification patients are divided into four groups: Group A: Good general condition; inactive colitis; Group B: Good general condition; mild active colitis; Group C: Poor general condition and/or severe active colitis; Group D: Critically-ill patients treated by emergency operations.

In this study an emergency operation is defined as one undertaken outside a normal operating list or within 12 hours of the decision to operate being taken-or both. The assessment relates to the immediate preoperative clinical condition and is an estimate of the severity of the disease at the time of the first definitive operation (table III).

It is interesting that the present sample over a six-year period is similar both numerically and on analysis to that studied in the last survey over a 12-year period. Thus, though almost twice as many patients are being operated on at these hospitals compared with 10 years ago, they are clinically very similar. This gives added points to the surgical results analysed later.

\section{Types of Operation}

Table IV shows the main operations carried out. The increasing incidence of one-stage total proctocolectomy and ileostomy shown over the years of the last survey has continued. If patients treated by colectomy and ileorectal anastomosis alone in the present study are omitted for an accurate comparison, then the incidence of one-stage proctocolectomy was: 1955-60, 24 out of $131(18.3 \%) ; 1961-6,66$ out of $196(33.7 \%)$; 1967-72, 114 out of $272(41.9 \%)$. The percentage of patients treated by colectomy and ileostomy has changed little over the 18 years reviewed $(1955-60,43.5 \% ; 1961-6,42.8 \% ; 1967-72,41.2 \%)$ and the frequency of this operation is now the same as that of total proctocolectomy.

TABLE IV-Types of Initial Operation in 294 Patients

\begin{tabular}{|c|c|c|c|c|c|c|}
\hline & & & & . & & $\begin{array}{l}\text { No. of } \\
\text { Patients }\end{array}$ \\
\hline Total proctocolectomy .. & .. & .. & .. & .. & .. & 114 \\
\hline Colectomy and ileostomy $\ldots$ & .. & . & .. & .. & . & 112 \\
\hline Colectomy and ileorectal anastomosis. . & .. & . & .. & .. & . & 31 \\
\hline $\begin{array}{llll}\text { Other operations } & \ldots & \ldots & \ldots\end{array}$ & .. & .. & . & .. & .. & 37 \\
\hline
\end{tabular}

Other operations were performed on 37 patients, involving an ileostomy in 34 cases and a colostomy in three. These operations were usually either ileostomy alone in the first instance or the removal of the colon in two stages. The diagnosis was Crohn's disease in eight of these patients. There was a fall from $21 \cdot 1 \%$ in these "non-standard" operations in the years 1955-66 to $13.6 \%$ in the years 1967-72.

Colectomy and ileorectal anastomosis was the first operation in 31 patients. In 22 of them this was the only surgical procedure that had been carried out when the case notes were studied, while in nine patients the anastomosis had been taken down and an ileostomy established. Of the patients first treated by colectomy and ileostomy nine underwent a subsequent ileorectal anastomosis.

\section{EXCISION OF RECTUM}

The rectum was excised alone in 54 patients and with other surgery in 13 patients. (This excludes those treated by a onestage proctocolectomy and ileostomy.) Four patients in the former group and two in the latter group died; these deaths are included in the section on operative mortality. If the patients with an ileorectal anastomosis are excluded, there were 26 patients alive when the case notes were studied in whom the rectum had not been excised.

\section{Postoperative Mortality of Primary Surgery}

There were 70 postoperative deaths, defined as deaths after surgery while the patient was still in hospital. All but five occurred within 28 days of operation. The mortality of the primary surgery was, therefore, $23 \cdot 7 \%$.

Of 114 patients who had total proctocolectomy $14(12 \cdot 3 \%)$ died. Of 112 patients treated by colectomy and ileostomy $35(31.2 \%)$ died and there were four deaths after a subsequent rectal excision at the same admission. There were 13 deaths among the 37 patients treated by other operations; in addition, one patient successfully treated as an emergency by right hemicolectomy and ileostomy died after left hemicolectomy and rectal excision at a later admission. Two patients died after colectomy and ileorectal anastomosis: an ileostomy was established in one shortly before death. A third patient died after ileorectal anastomosis after an earlier colectomy and ileostomy.

\section{POSTOPERATIVE MORTALITY AND PREOPERATIVE GRADING}

In patients treated by elective operation ( $A$ and $B$ cases) there was a low operative mortality for all types of surgery: the figures were three deaths after 140 operations $(2 \cdot 1 \%$ ) (table V).

TABLE v-Postoperative Mortality and Preoperative Grading. Results expressed as Number of Patients who Died/Number of Patients

\begin{tabular}{|c|c|c|c|c|c|}
\hline Operation & $\begin{array}{c}A \text { and } B \\
\text { Cases }\end{array}$ & $\underset{\text { Cases }}{\mathrm{C}}$ & $\begin{array}{c}\text { D } \\
\text { Cases }\end{array}$ & Unknown & Total \\
\hline Total proctocolectomy & $1 / 78$ & $8 / 30$ & $4 / 4$ & $1 / 2$ & $14 / 114$ \\
\hline $\begin{array}{l}\text { Colectomy and } \\
\text { ileostomy } \\
\text { Other operations } \\
\text { Colectomy and } \\
\text { ileorectal } \\
\text { anastomosis }\end{array}$ & $\begin{array}{l}1 / 34 \\
0 / 3 \\
1 / 25\end{array}$ & $\begin{array}{c}20 / 45 \\
1 / 5 \\
1 / 5 \\
\end{array}$ & $\begin{array}{r}14 / 32 \\
8 / 10 \\
- \\
\end{array}$ & $\begin{array}{l}0 / 1 \\
4 / 19 \\
0 / 1\end{array}$ & $\begin{array}{c}35 / 112 \\
13 / 37 \\
2 / 31 \\
\end{array}$ \\
\hline Total & $3 / 140$ & $30 / 85$ & $26 / 46$ & $5 / 23$ & $64 / 294$ \\
\hline
\end{tabular}


TABLE VI-Age in relation to Operative Mortality in 131 Patients Coming to Urgent or Emergency Surgery

\begin{tabular}{|c|c|c|c|c|c|c|c|c|}
\hline $\begin{array}{c}\text { Age in Years } \\
\text { No. who Died/No. of Patients }\end{array}$ & $\begin{array}{c}<20 \\
0 / 4(0 \%)\end{array}$ & $3 / 17(17 \cdot 6 \%)$ & $5 / 20(25 \%)$ & $6 / 20(30 \%)$ & $13 / 31(41 \cdot 9 \%)$ & $20 / 23(87 \%)$ & $\left.10 / 13^{70-76} \cdot 9 \%\right)$ & $3 / 3 \stackrel{3}{(100 \%)}$ \\
\hline
\end{tabular}

The four patients who died following rectal excision after an initial colectomy and ileostomy are included in this table.

For patients treated by urgent operation (C cases) the overall operative mortality was $37.6 \%$ (32 out of 85 ). The figure was $26.7 \%$ for patients undergoing proctocolectomy (8 out of 30 ), $44.4 \%$ for those initially treated by colectomy and ileostomy ( 20 out of 45), with two further deaths after rectal excision during the same admission, and $20.0 \%$ for patients treated either by other operations or by colectomy and ileorectal anastomosis (one patient out of five in each case).

The total operative mortality for patients coming to emergency surgery (D cases) was $60.9 \%$ (28 out of 46 ). The figure was $100 \%$ for proctocolectomy (4 out of 4 ), $43.8 \%$ for those treated by colectomy and ileostomy (14 out of 32), with two further deaths after rectal excision at the same admission, and $80 \%$ ( 8 out of 10 ) for patients undergoing other operations.

As the operative mortality for elective surgery was very low, these patients will not be analysed further. Postoperative mortality in patients coming to urgent and emergency surgery (C and $\mathrm{D}$ cases) will be considered in relation to age, length of history, interval between admission and surgery, and the presence or absence of colonic perforation.

The outcome of urgent or emergency surgery was clearly related to the age of the patient (table VI). The mortality was $22.9 \%$ in the 61 patients under 50 years of age and $65.7 \%$ for the 70 patients aged 50 years and over.

The length of history up to operation was known in 127 of the 131 patients in groups $C$ and $D$. Of the 48 patients with a history of less than three months 26 died postoperatively $(54.2 \%)$. Of the 79 patients with a history of three months or more 31 died $(39 \cdot 2 \%)$.

The number of days between admission and operation varied from 1 to 80 for patients in group $C$ and from 0 to 99 for those in group D (table VII). However, in both these groups there appeared to be little correlation between increasing delay before operation and postoperative death.

TABLE VII-Interval Between Admission and Operation in 85 Grade C Cases and 46 Grade $D$ Cases

\begin{tabular}{|c|c|c|c|c|c|c|}
\hline Interval in days: & $0-$ & $10-$ & $20-$ & $30-$ & $40-$ & $\geqslant 50$ \\
\hline 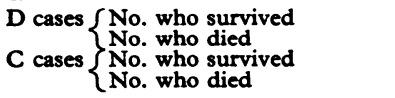 & $\begin{array}{r}10 \\
11 \\
14 \\
6\end{array}$ & $\begin{array}{r}4 \\
10 \\
16 \\
11\end{array}$ & $\begin{array}{l}4 \\
4 \\
9 \\
5\end{array}$ & $\begin{array}{l}0 \\
0 \\
9 \\
3\end{array}$ & $\begin{array}{l}0 \\
0 \\
4 \\
3\end{array}$ & $\begin{array}{l}0 \\
3 \\
1 \\
4\end{array}$ \\
\hline
\end{tabular}

In 35 patients the colon had perforated preoperatively (sealed in 11 patients, with abscess formation in three, and "free" in 21 patients). In one patient with Crohn's disease there was an ileal perforation. Of these patients $24(66.7 \%)$ died-one after colectomy following an initial ileostomy, one after rectal excision 19 days after colectomy and ileostomy, and 22 after the primary operation.

In the 35 patients with ulcerative colitis the site of the perforation was mentioned in 32 cases. There were multiple perforations in 12 patients while the site in those with single perforations was as follows: caecum, three; hepatic flexure, one; transverse colon, six; splenic flexure, one; descending colon, two; and sigmoid colon, seven. If the patient with Crohn's disease is excluded, 21 of these patients perforated during the first attack of the disease and seven patients during a relapse. In seven patients this point could not be determined accurately. Out of 70 patients who died postoperatively (see table VIII), the diagnosis was Crohn's disease in seven.
TABLE viII-Causes of Postoperative Death in 70 Patients

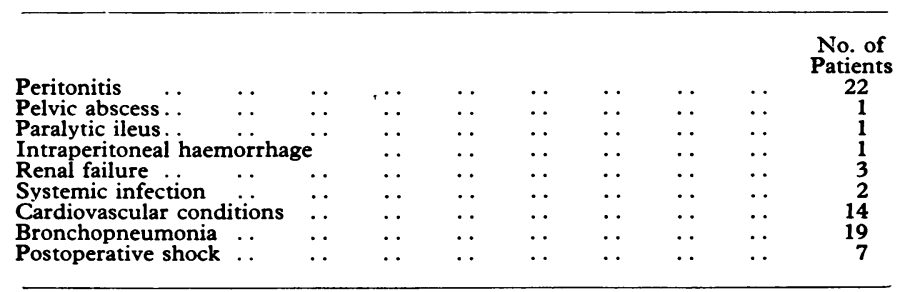

\section{Postoperative Complications}

The incidence of postoperative complications in patients treated by total proctocolectomy or colectomy and ileostomy is shown in table IX. Major complications are defined as those which are potentially life-threatening and minor complications as any other condition which interrupts the course of convalescence. When the operative deaths are excluded, 21 patients $(19 \cdot 1 \%)$ developed major complications after elective surgery (A and B cases), 15 patients $(31.9 \%)$ after urgent surgery (C cases), and 10 patients $(55.5 \%)$ after emergency operations (D cases).

The major complications were as follows: intra-abdominal infection in six patients; intestinal obstruction in three; other abdominal complications in six; severe abdominal wound infection or dehiscence in ten; deep venous thrombosis in five; pulmonary complications in five; electrolyte problems in three; miscellaneous complications in four; and severe haemorrhage (from the rectum in three and the perineum in one) in four patients.

TABLE IX-Incidence of Postoperative Complications in Patients Undergoing Total Proctocolectomy or Colectomy and Ileostomy

\begin{tabular}{|c|c|c|c|c|c|}
\hline \multirow{2}{*}{ Preoperative Grade } & \multirow{2}{*}{$\begin{array}{l}\text { No. of } \\
\text { Patients }\end{array}$} & \multirow{2}{*}{$\begin{array}{c}\text { No. of } \\
\text { Post- } \\
\text { operative } \\
\text { Deaths }\end{array}$} & \multicolumn{3}{|c|}{ Complications in Survivors } \\
\hline & & & Major & Minor & None \\
\hline $\begin{array}{c}A \text { and } B \\
\text { C } \\
D\end{array}$ & $\begin{array}{r}112 \\
75 \\
36\end{array}$ & $\begin{array}{r}2 \\
28 \\
18\end{array}$ & $\begin{array}{l}21 \\
15 \\
10\end{array}$ & $\begin{array}{r}29 \\
13 \\
4\end{array}$ & $\begin{array}{r}60 \\
19 \\
4\end{array}$ \\
\hline
\end{tabular}

CARCINOMA OF COLON OR RECTUM

Invasive carcinoma was found in $\mathbf{1 0}$ of the patients with ulcerative colitis $(3.9 \%)$. This incidence is very similar to that found in the previous survey (13 patients out of 311 ). With the exception of one patient aged 25 years at the time of operation, the age range was from 45 to 60 years; 8 of the 10 patients had a history of colitis for more than 10 years and the six patients still alive when the case notes were studied had been followed up for intervals of five months to 4 years 11 months.

Interestingly, one patient with a history of diarrhoea for more than 10 years had apparently never previously attended hospital for his complaint.

\section{LATE COMPLICATIONS OF SURGERY}

These complications have not been dealt with in detail as this has been done in previous studies. ${ }^{13}$ Three of the most common complications will be mentioned briefly in order of importance.

Complete small bowel obstruction developed in 19 of the 272 patients with an ileostomy. In six patients the obstruction 
occurred in the postoperative period and in the other 13 patients at intervals from one month to two and a half years after surgery. Adhesions were responsible in 14 of the 19 patients and in 12 of the 13 readmitted with obstruction. Three of the patients readmitted with obstruction died: two after laparotomy and one shortly after admission before operation could be undertaken.

Reconstruction or resiting of the ileostomy was required in 23 patients with a total of 32 operations. In eight patients reconstruction was necessary in the postoperative period, in five patients with later operations, and 14 patients were readmitted for this surgery alone. One patient in this group died after an emergency operation for a prolapsed and gangrenous ileostomy.

Of 161 patients who left hospital with a perineal wound, 20 patients $(12 \cdot 3 \%)$ with a total of 31 admissions were readmitted for treatment to the wound. The date of healing was known in 109 patients and was within six months in 56 patients $(51.4 \%)$, in 6 to 12 months in 23 patients $(21.1 \%)$ and was greater than one year in 30 patients $(27.5 \%)$.

\section{Discussion}

This survey covers the work of more than 60 surgeons operating in 34 hospitals of the region. The pattern of the surgery used in treating these patients reveals some interesting features. Onestage total proctocolectomy and ileostomy is becoming considerably more frequent, particularly for patients treated electively. Colectomy and ileostomy as an elective procedure was undertaken in only 34 patients compared with 78 similar patients treated by proctocolectomy. For patients having urgent and especially emergency surgery, however, the lesser procedure was much more frequently undertaken. Ileorectal anastomosis was carried out as a one or two-stage operation in $\mathbf{4 0}$ patients and in $31(10.5 \%$ of the total) as the first operation. Though comparison with previous years is impossible, it is interesting that at the present time this is considered to be a suitable operation for one in every 10 patients in the first instance.

A discussion of the results of surgical treatment for these diseases in this unselected group of patients becomes essentially an analysis of the results of surgery for acute colitis. The discrepancy between the low operative mortality for elective surgery and the high mortality for acute surgery is obvious from the results. Moreover, the mortality for acute surgery has not decreased over the 18 years in which these hospitals have been studied. If only patients treated by standard surgery-that is, total proctocolectomy or colectomy and ileostomy-are considered, then the figures are as follows: $1955-60,28 \cdot 2 \%$ (11 out of 39 ), $1961-6,26.4 \%$ (19 out of 72), and for the years 1967-72, $41 \cdot 4 \%$ (46 out of 111 ) table X).

TABLE X-Operative Mortality in Patients coming to Urgent or Emergency Surgery and Treated by Total Proctocolectomy or Colectomy and Ileostomy

\begin{tabular}{c|c|c|c}
\hline $\begin{array}{c}\text { Years of Survey } \\
\text { No. who died/No. of Patients }\end{array}$ & $11955-1960$ & $1961-1966$ & $1967-1972$ \\
\hline
\end{tabular}

single factor leading to this delay was the omission of sigmoidoscopy as a ward procedure. There was a lack of appreciation of the information often to be gained from a plain abdominal $x$-ray film and the use of such a film in the acute case, when a barium enema examination might well be dangerous, was not widely enough recognized. Often several days would elapse before a barium enema could be performed and a decision about treatment was deferred until the result was available.

Misdiagnosis was infrequent but included carcinoma, an acute exacerbation of diverticular disease, and on occasion intestinal obstruction when abdominal distension was present on admission.

Once the diagnosis had been made, the medical treatment begun tended to underestimate the severity of the disease: the use of salazopyrin and steroid enemas as the only treatment for acute disease was too often seen. Steroid therapy, though widely used, was sometimes begun in low dosage and increased when there was no clinical improvement rather than with the more effective initial high dosage decreasing as response occurred. There appeared to be a lack of recognition of how dangerous an attack of colitis can rapidly become and a sense of urgency about treatment often was not apparent. Medical treatment was continued for too long when response was minimal or the patient's condition had become stationary after an initial improvement. More dangerously, medical management was maintained for days or even weeks with clinical evidence of abdominal distension and/or dilatation of the transverse colon shown radiologically. These signs were present in 34 patients for two days or more preoperatively, and in 14 patients for 10 days or more. Of these 34 patients 20 died.

I think that the poor surgical results are mainly attributable to the general delay in obtaining a surgical opinion; occasionally the notes actually stated that this should be sought only if some catastrophe occurred-for example, acute deterioration in the general condition, or perforation. Once the patient had been seen by the surgeon, operation was usually undertaken without delay. Surgeons are fully aware of the dangers of procrastination: the difficulties of surgery with established colonic dilatation, the danger of perforation of the colon when handled, and the high postoperative mortality under these circumstances. If the disease has progressed to perforation, then the high postoperative mortality, even in the most expert hands, is well known.

The treatment of severe acute colitis must be by a co-operative approach by both physician and surgeon; the opinion of a surgeon should be sought at the outset and the care of the patient undertaken jointly. This cannot be stated too forcefully. A definite length of time for continuing medical treatment cannot be suggested: this will obviously depend on the degree of response. But undoubtedly an improvement in results can come only when both the physician and the surgeon agree on the correct timing for colectomy. This joint approach must lead to earlier surgical intervention and perhaps a few patients will be treated surgically when a remission could have been achieved by medical measures. However, more importantly the incidence of long-standing colonic dilatation or perforation -or bothwhich were largely responsible for the high mortality in this series, will surely be reduced.

\section{LATE COMPLICATIONS}

The incidence of late complications continues to be high. Though the follow-up was incomplete, 59 of the 205 patients who left hospital with an ileostomy had required readmission. The most important late complication of ileostomy and excisional surgery is small bowel obstruction: the readmission rate of $6.3 \%$ (13 out of 205) for obstruction treated surgically is similar to that found in previous studies. It remains a fairly frequent occurrence, and the implications of delayed diagnosis are obvious from the fact that three patients in this series died. This cause of death might be largely eliminated if patients and all medical 
personnel were fully aware of the possibility of this complication, the symptoms to be expected, and the necessity for urgent hospital admission for possible early laparotomy.

Reconstruction of the ileostomy (usually for stenosis or retraction) continues to be necessary in $8 \%$ of patients but other stomal problems, particularly with the peristomal skin, have definitely decreased. A very great improvement in the field of stoma care has occurred recently. Delayed healing of the perineal wound continues to be frequent; the finding that only half the wounds were healed in less than six months and about $75 \%$ in a year is the same as in previous studies. One in every eight patients who left hospital with a perineal wound required further inpatient treatment for it; this readmission rate is again similar to previous figures.

An important aspect of the follow-up of these patients needs to be emphasized. The dangers of the development of carcinoma in the rectal stump when this has been left after colectomy and ileostomy and in the retained rectum after colectomy and ileorectal anastomosis have already been reported. ${ }^{45}$ In this series the follow-up of these two groups of patients, particularly the former, was not as thorough as is warranted by these facts. The difficulties of recalling patients who fail to keep outpatient appointments are well known, but all patients who have been treated surgically for ulcerative colitis and in whom the rectum has not been excised should be seen at six-monthly intervals for examination, which should include sigmoidoscopy and prefer- ably rectal biopsy examination to detect premalignant mucosal changes.

This paper intended to present an up-to-date picture of the results of surgery for inflammatory bowel disease in an unselected group of patients. The survey showed the continuing existence of several problems relating to the treatment of these patients which require more detailed consideration. These will be discussed more fully at a later date.

I am very grateful to the surgeons of the North-east Metropolitan Hospital Region for permission to study the case records of patients under their care.

My thanks are due to Mrs. S. M. Ritchie, M.B., B.S., for help in the field work and to the medical records officers of the region for their co-operation.

I acknowledge with thanks the helpful criticism of Dr. J. E. Lennard-Jones in the preparation of this paper.

The survey was undertaken with the aid of a grant from the Ileostomy Association of Great Britain and Ireland.

\section{References}

1 Ritchie, J. K., Gut, 1971, 12, 528.

2 Ewart, W. B., and Lennard-Jones, J. E., Lancet, 1960, 2, 60.

3 Ritchie, J. K., British Fournal of Surgery, 1972, 59, 345.

Ritchie, J. K., Proceedings of the Royal Society of Medicine, 1972, 65, 73.

5 Aylett, S., British Medical Fournal, 1971, 2, 203.

\title{
Psychiatric Morbidity and Referral on Two General Medical Wards
}

\author{
G. P. MAGUiRE, D. L. JULIER, K. E. HAWTON, J. H. J. BANCROFT
}

British Medical fournal, 1974, 1, 268-270

\section{Summary}

Psychiatric morbidity among 230 medical inpatients was determined by a two-stage screening procedure, using the General Health Questionnaire and Standardized Psychiatric Interview. Of these patients, $23 \%$ were considered psychiatrically ill, affective disonders being the commonest illnesses encountered; and $27(12 \%)$ were psychiatrically referred. While referral was related to severity of psychiatric illness and previous psychiatric illness, the degree to which the psychiatric illness obtruded or created problems in management appeared more crucial in determining referral. In half of those with psychiatric illness the problems did not appear to have been detected or dealt with. It is suggested that medical clerking should routinely include questions about mood and psychological responses to illness.

\footnotetext{
University Department of Psychiatry, Warneford Hospital, Oxford OX3 7JX

G. P. MAGUIRE, M.R.C.PSYCH., D.P.M., Clinical Tutor in Psychiatry D. L. JULIER, M.R.C.P., M.R.c.PSYCH., Senior Research Psychiatrist K. E. HAWTON, M.B., D.P.M., Registrar in Psychiatry

J. H. J. BANCROFT, M.D., M.R.C.PSYCH., First Assistant in Psychiatry
}

\section{Introduction}

Psychiatric services to the general medical wards are usually based on referrals initiated by physicians. ${ }^{1-4}$ Yet medical staff probably fail to recognize, treat, or refer many of those patients who might benefit from psychiatric help, ${ }^{56}$ even when they liaise closely with a psychiatrist. ${ }^{7}$ Despite this evidence there has been little direct study of the problem. ${ }^{8} \mathrm{We}$ therefore set out to study psychiatric morbidity and referral among the inpatients of two general medical wards in a teaching hospital.

\section{Patients and Methods}

All patients consecutively admitted to two medical wards during November and December 1971 were included, provided they were judged independently by the medical teams to be well enough to participate, and had not been admitted after a suicide attempt. The male and female medical wards chosen for study were the responsibility of four physicians, who, in addition to their particular interests in candiovascular, endocrine, metabolic, and renal diseases, took their share of acute medical admissions.

Our psychiatric assessment was carried out in two stages. Firstly, patients were asked to complete the General Health Questionnaire $^{9}$ as soon as possible after admission. All those who scored over 11-that is, within the range of probable psychiatric morbidity-were given the Standardized Psychiatric Interview ${ }^{10}$ by an experienced psychiatrist. 